\title{
WHAT PSYCHOTHERAPISTS CAN BEGIN TO LEARN FROM NEUROSCIENCE: SEVEN PRINCIPLES OF A BRAIN-BASED PSYCHOTHERAPY
}

\author{
NYDIA M. CAPPAS, RAQUEL ANDRES-HYMAN, AND LARRY DAVIDSON \\ Yale University School of Medicine
}

Advances in neuroscience provide guidance for the development of psychological conceptualizations of mental illness and treatment that go beyond a reductionistic biological etiology. The authors propose that these advances can be translated into practical clinical applications. Through the elaboration of 7 principles that can be helpful in using neuroscience to enhance clinical practice, this article describes areas of neuroscientific knowledge with particular relevance to psychotherapy.

We know two kinds of things about what we call our psyche (or mental life): first, its bodily organ and scene of action, the brain (or nervous system) and, on the other hand, our acts of consciousness. ... Everything that lies between is unknown to us, and the data do not include any direct relation between these two terminal points of our knowledge.

-Freud, An Outline of Psycho-Analysis

While researchers admittedly still have a long way to go, current understandings of the brain are beginning to shed light on this unknown territory of Freud's (1949) "in between." In a groundbreaking article entitled "A New Intellectual Framework for Psychiatry," Nobel Prize winner Eric Kandel (1998) proposed several principles for informing psychological thinking with the advances made by the neurosciences over the last century. Most notably, he proposed that "all mental processes, even the most complex psychological processes, derive from operations of the

Nydia M. Cappas, Raquel Andres-Hyman, and Larry Davidson, Department of Psychiatry, Yale University School of Medicine.

Correspondence regarding this article should be addressed to Nydia M. Cappas, PsyD, Program for Recovery and Community Health, Department of Psychiatry, Yale University School of Medicine, Erector Square 6 West, Suite 1C, 319 Peck Street, New Haven, CT 06513. E-mail: ncappas@ yahoo.com brain" (p. 460). Elaborating on this brainbehavior connection, he further suggested that "altered genes do not, by themselves, explain all of the variance of a given major mental illness" (p. 460), leaving ample room for experience and environment to exert influence on neural development and functioning. On the side of practice, Kandel similarly pointed out that "insofar as psychotherapy or counseling is effective ... it presumably does so through learning, by producing changes in gene expression that alter the strength of synaptic connections" (p. 460). It is thus when situated within the context of neuroscience that psychology and clinical practice are best viewed as offering possible means of understanding and modifying the brain.

Despite the wealth of findings on which Kandel (1998) drew, the convergence of neuroscience and psychology is often limited to efforts to find the biological etiology of mental disease, resulting in views that reduce human nature and suffering to biochemical malfunctions. Recent advances in neural science support the need to move beyond a reductionistic etiology to a more complex conceptualization of human experience and allow researchers to begin to translate findings from neuroscience into their practical clinical applications. Through such a process, neuroscience can be useful to psychotherapy in at least two ways: through validation of existing psychotherapeutic theories and interventions, on the one hand, and, alternatively, by suggesting directions to enhance current clinical practice on the other.

Although transforming esoteric neuroscientific findings into practical applications can be challenging, it is not without precedent. Caine and Caine (1994) compiled the growing literature concerning brain functioning and used it to inform the development of 12 principles of brainbased learning for use in educational settings. For example, the authors asserted in one principle that the brain is a parallel processor. On the basis of this insight, they deduced that an effective teaching strategy involves stimulating several 
modalities, rather than focusing on one alone, to maximize information processing. Similarly, the following discussion points to several implications of brain functioning for clinical practice and the development of more effective therapeutic strategies. Inspired by Kandel's (1998) groundbreaking article and Caine and Caine's model of brain-based learning, we have identified seven principles of neuroscience with particular relevance to clinical practice. In illustrating some of these principles, we reference clinical approaches that reflect particular schools of thought, though these principles are applicable across theoretical orientations. In addition, it is worthwhile to note that this discussion is limited by our current understanding of neuroscience. As new discoveries are made in the areas of genetics, neuroscience, sociology, immunology, and psychology, researchers and practitioners can look forward to the elaboration and revision of these principles as well as the creation of new ones.

\section{Seven Principles of Brain-Based Psychotherapy}

\section{Principle 1: Genetics and Environment Interact in the Brain to Shape the Individual}

The field of genetics has made valuable contributions concerning the etiology of various dysfunctions. However, genetic conceptualizations of mental illness have also promulgated the mistaken notion that mental illness and personality traits are untreatable or immutable (Appell, 2002). This perspective is reminiscent of the nature standpoint of the long-standing "nature versus nurture" debate that discounts the role of environment in influencing behavior. In truth, nature and nurture are equally capable of creating and modifying the structures of the brain, neural chemistry, and therefore human behavior. Genes and experience modify the brain through the same mechanism, that is, through the modification of synapses. Whereas genes accomplish this through protein synthesis, prewiring, and the generation of synaptic connections, experience wires the brain through learning, a process that influences gene expression and the strength of synaptic connections. As Kandel (1998) described,

Stated simply, the regulation of gene expression by social factors makes all bodily functions, including all functions of the brain, susceptible to social influences. These social influences will be biologically incorporated in the altered expres- sions of specific genes in specific nerve cells of specific regions of the brain. These socially influenced alterations are transmitted culturally. They are not incorporated in the sperm and egg and therefore are not transmitted genetically. In humans the modifiability of gene expression through learning (in a nontransmissible way) is particularly effective and has led to a new kind of evolution: cultural evolution. The capability of learning is so highly developed in humans that humankind changes much more by cultural evolution than by biological evolution. (p. 461)

Kandel's description of the influence of culture on genetics opens the door to discussion concerning interactions between genes and environment. No longer would genetic explanations carry an irreversible stamp. Rather, genetic influences represent one of many factors that influence human behavior.

Implications for clinical practice. Psychotherapy, as a strategic and purposeful environmental influence intended to enhance learning, may be a particularly effective means of shaping the expression of genes. Individuals with mental illness or a family history of mental illness or substance abuse may benefit from the awareness that hereditary predisposition is a far cry from genetic predestination; that even at a fundamental genetic level, change is possible. At the same time, the importance of environmental influences suggests the possibility that the customary emphasis placed on family history of mental illness in evaluating prognosis may be overstated. This is of particular relevance in light of findings that both the practitioner's and patient's belief in the possibility of change are powerful predictors of recovery (Frank \& Frank, 1993; Leake \& King, 1977). When told that they will have a mental illness for the rest of their lives and should give up their hopes and dreams for a productive life, many people understandably give up. Educating practitioners and patients about the influence of the environment on the human brain and the possibility of change, even in the face of mental illnesses with strong hereditary links, has the potential to instill hopefulness and inspire movement toward recovery.

\section{Principle 2: Experience Transforms the Brain}

Philosophers, theologians, and poets have marveled at the transformative potential of some experiences, noting with wonder the capacity of an event to upend a person's world. In these moments, it seems as if people are permanently altered. Afterward, it seems that their 
brains are not the same either. Circuits in the brain change in response to environmental challenges such as development, injury, learning, and memory (Squire \& Kandel, 1999). Plasticity, through the process of long-term potentiation, is the manner by which humans create and modify neuronal connections in response to experience (Dudai, 2002; Squire \& Kandel, 1999). Long-term potentiation is an increase in the efficacy of synapses as a result of a high-frequency stimulus lasting from hours to days (Dudai, 2002). In other words, a stimulus in the form of a new experience alternately strengthens or weakens neural connections.

The brain is also capable of renewing itself. For a number of years, it was believed that human beings were born with a finite number of neurons. Until recently, neurogenesis, or the birth of new neurons, was a process thought to be impossible in humans. It is now understood that humans have the capacity for neurogenesis and that this capacity is retained throughout the life span (Eriksson et al., 1998; Gross, 2000). Moreover, neurons generated in the brain as a result of experience not only become functional but are associated with improved memory and plasticity (Van Praag et al., 2002).

Implications for clinical practice. The areas of the brain associated with emotions and memories are highly plastic; among them are the prefrontal cortex, the amygdala, and the hippocampus (Davidson, Jackson, \& Kalin, 2000). Arguably, contemporary clinical approaches to the treatment of mental illness are highly evocative of memory and emotion, indicating that therapy targets the very areas of the brain most amenable to neuronal change and neurogenesis (Davidson et al., 2000). In fact, Cozzolino (2002) proposes that "all forms of therapy, regardless of theoretical orientation, will be successful to the degree to which they foster neural growth and integration" (p. 27).

The capacity for psychotherapy to transform through learning not only what was previously thought to be psychological but also its physiological substrate has important implications for clinical practice. In a society beset by cartoon advertisements for pharmaceutical drugs to remedy the chemical imbalances of the mentally ill, evidence that learning can be a viable means of forging lasting neural change (as well as emotional and behavioral change) is heartening. Contrary to conventional wisdom, it appears that one can, in fact, teach an old dog new tricks. Perhaps for this reason research has upheld the superior efficacy of a combination of psychotherapy and medication, rather than either in isolation, for the treatment of mental illness (Karasu, 1990; Paykel, 1995).

The case of Jaime, a man 27 years of age in outpatient treatment for schizophrenia, provides a useful example. Following a series of relapses, Jaime expressed hopelessness about his ability to manage his illness and exert control over his life. During a period of time in which his symptoms abated and Jaime was feeling better, his therapist would ask what he had done to make it so, to which Jaime replied "I don't know" or "must be the medication working." In response, the therapist explained that, whereas medication use was important, Jaime might also be making important changes that affected his condition, therefore altering his brain in a positive way. After several sessions, Jaime reported that he felt more in control of his life and the course of his illness. He began participating in sports and other social and recreational activities, and his psychiatrist, noting his improvement in functioning, lowered his medication dosage. Although impossible to know for certain, Jaime's knowledge of his own capacity to change his physiology seemed to promote an increased sense of self-efficacy that led him to purposefully seek change.

\section{Principle 3: Memory Systems in the Brain Are Interactive}

Memory is the process by which knowledge is acquired, codified, stored, and retrieved (Kandel, Schwartz, \& Jessell, 2000). The brain regions associated with long-term memory processes include the medial temporal lobe and the prefrontal cortex (Ingvar \& Petterson, 2000). Once an event takes place or information is learned, the hippocampus begins processing that information, the consolidation of which can occur over a period of years (Haist, Gore, \& Mao, 2001). The information then remains dependent on this structure until it becomes old knowledge, at which point it is organized in the neocortex (see Eichenbaum, 2001, for a review).

Instead of being a perfect account of what happened, memories can be constructed at the time of retrieval in accordance with the method used to retrieve it (Gonsalves \& Paller, 2000; Shacter, 1996). For example, a stimulus such as a 
question, photograph, or scent can interact with a particular memory resulting in a modification (Nadel \& Land, 2000).

Sense of well-being and the development of personality and emotions are clearly tied to the capacity to store and retrieve the information gathered in everyday life (Conway, 2003). The ability to summon "the conscious mental reenactment of personally experienced past events" is otherwise known as episodic memory (Dudai, 2002, p. 91). In other words, episodic memory (also called autobiographical memory) is the method by which people weave their personal stories. With increasing life experience, narratives are interlaced with one another to create a self-story. As Garry and Polaschek (1999) pointed out,

The "autobiographical memories" that tell the story of our lives are always undergoing revision precisely because our sense of self is too. We are continually extracting new information from old experiences and filling in gaps in ways that serve some current demand. Consciously or not, we use imagination to reinvent our past, and with it, our present and future. (p. 66)

Implications for clinical practice. Because the context in which a memory is evoked can modify it, it is possible to shape the manner in which painful experiences are remembered and integrated. In fact, this is common practice in some forms of psychotherapy such as narrative therapy. From this perspective, "a narrative is like a thread that weaves the events together, forming a story" (Morgan, 2000, p. 5). At the center of the intervention is the revision of dominant individual narratives, those that shape behavior and the perception of oneself and others, to emphasize positive remembrances that better serve everyday functioning. This is accomplished by acknowledging the dominant narrative while assisting the patient to construct an alternative, more adaptive account. The following example is illustrative.

A 27-year-old mother of four described being tormented by memories. She was depressed with recurrent suicidal thoughts owing in part to a persistent belief that God had punished and abandoned her. After several sessions during which a strong therapeutic alliance was established, the practitioner noted that in every difficult moment in the woman's life she had encountered someone who helped her in some way to get through it. When she voiced this observation to her patient, the woman wondered if this reflected an act of
God. Her narrative of abandonment gradually evolved into a story of endurance and friendship. By attending to the neglected elements of the woman's dominant narrative, the practitioner assisted the woman to transform her perception of her life from one of worthlessness into one of meaning and value.

Whereas the malleability of memories can be beneficial, the human propensity to fill in gaps in memory may lead to the error of believing that something repeated or visualized actually happened (Hyman \& Pentland, 1996). For example, Braun, Ellis, and Loftus (2002) designed a study examining the interactive nature of memories in which participants were shown an advertisement displaying patrons at Disney World shaking hands with Bugs Bunny. Later they were asked if they recalled seeing Bugs Bunny during their own Disney World vacation. Though impossible because Bugs Bunny is not a Disney character, many people reported having seen him. In the experimental condition, this mistake was harmless; however, the suggestibility of memory can be extremely delicate in cases of a legal nature (Brahams, 2000; Loftus, 2003).

Because memory is susceptible to suggestive influences, practitioners must tread cautiously when working with memories of abuse (Loftus, 1997). However, amnesia after a traumatic event and recovered memories of abuse are common and well-documented phenomena (Scheflin \& Brown, 1996; van der Kolk \& Fisler, 1995) that should not be ignored at the expense of trauma victims. The debate over recovered memories of abuse is extensive and will not be resolved here. There is clear neuroscientific evidence, however, in support of the detrimental effects of trauma on memory (McEwen \& Sapolsky, 1995) as well as mechanisms for repressing a traumatic event (Anderson \& Green, 2001). Caution should not be confused with skepticism, and practitioners should strive to critically understand the underpinnings of memory to better serve their clients in both clinical and legal contexts.

\section{Principle 4: Cognitive and Emotional Processes Work in Partnership}

Arnold Bennett (1897), a renowned English novelist, wrote the following: "There can be no knowledge without emotion. We may be aware of a truth, yet until we have felt its force, it is not ours. To the cognition of the brain must be added 
the experience of the soul" (II 57). Despite these sage words, a dichotomized view of emotions and reason has permeated human culture. Historically, emotions have been perceived as an obstruction to reason, requiring containment under reason's authority. However, increasingly neuroscience has illuminated the processes underlying emotion and reasoning, suggesting that in place of this reputed antagonism the two actually work in partnership (Shacter, 1996). Appealing to one necessarily involves appealing to the other.

Emotions can be defined as bodily responses that have evolved by necessity and survival. Originating in the limbic system, emotions derive from the oldest structures of the brain (Le Doux, 1997). The fight or flight response, which is typical across species and developed from the need to survive, involves the activation of the central nervous system in response to a threatening stimulus. The activation of the central nervous system prepares the body for action, be it to fight or to escape. In contrast, feelings are "the mental representation of the physiological changes that characterize emotions" (Damasio, 2001, p. 781). In other words, feelings are the meaning humans assign to emotions. According to Damasio (2001), feelings serve the purpose of enhancing emotions to stimulate learning and anticipation of similar future events. The systems of the brain concerned with processing feelings differ from those that produce emotions. Contrary to emotions, which rely on subcortical regions of the brain - the amygdala and the ventromedial prefrontal cortices-feelings arise in the neocortical regions, systems associated with the assignment of meaning. Damasio (2003) summarized this distinction by stating, "Emotions play out in the theater of the body. Feelings play out in the theater of the mind" (p. 28). It is for this reason that humans are capable of confusing sadness with anger and anxiety with fear.

Memories, emotions, and feelings are also interconnected processes. McGaugh (2000) has described the intricate interactions between anatomical and chemical reactions created by emotions, which in turn influence (enhance or inhibit) memory consolidation. The amygdala, known for its important role in emotional arousal, has a critical role in mediating neuro-transmitters such as epinephrine and glucocorticoids essential for memory consolidation. Emotional arousal has the capacity to activate the amygdala, which in turn modulates the storage of memory (McGaugh, Ca- hill, \& Roozendaal, 1996). One of the most wellknown effects of negative emotion on the brain is high exposure to glucocorticoids (McEwen \& Sapolsky, 1995). In low levels, glucocorticoids can enhance memory. However, under high levels of prolonged stress, the level of glucocorticoids rise, damaging the cells of the hippocampus (Sapolsky, 1998). Numerous studies have uncovered structural reductions in the hippocampus in response to psychological trauma (Gilbertson et al., 2002), depression (Gartside, Leitch, McQuade, \& Swarbrick, 2003), and alcoholism (Ryabinin, 1998).

Implications for clinical practice. Emotions, feelings, and memory are cardinal components of psychotherapy. Understanding their neurocognitive interaction can serve the therapeutic process in multiple ways. For example, exploring the meanings of sensations and reactions in therapy as a way to influence decision making can be useful both to the client and to the therapist. Moreover, assisting in the process of assigning asserted meanings to emotions and teaching the client to understand the nature of emotional reactions can help modify unhealthy behavior patterns. One such example can be found in dialectical behavioral therapy in which clients are taught to observe and describe the components of their emotions as a way to understand their meaning and modify their reactions (Linehan, 1993).

The development of posttraumatic stress disorder (PTSD) in response to a traumatic event demonstrates the detrimental impact of negative emotion. According to the DSM-IV (American Psychiatric Association, 1994), this condition is characterized by recurrent intrusive recollections, dreams, and flashbacks of the traumatic event and/or numbness and avoidance of feelings and thoughts related to the event. The intrusiveness of memories in recurrent flashbacks and nightmares render memories a central component in the progression of this condition. Because intrusive memories can persist for years after the incident, PTSD is associated with a number of difficulties in the areas of personal and interpersonal functioning (Alpert, Brown, \& Courtois, 2000) and increased vulnerability to future stressful events.

Studies in psychology and neuroscience point to the possibility that PTSD may be prevented if researchers interrupt the overconsolidation of the traumatic memory (Wilson, Raphael, Meldrum, Bedosky, \& Sigman, 2000). It is possible that early intervention focused on the processing of 
the traumatic memory may help prevent the overconsolidation of the negative memories. Foa, Hearst-Ikeda, and Perry (1995), for example, used cognitive-behavioral therapy to treat people soon after a traumatic sexual or nonsexual assault. They found that the group that received therapy experienced significantly less PTSD symptomatology at 4 months. Furthermore, after treatment was completed, only $10 \%$ of the experimental group met the criteria for PTSD compared with $70 \%$ in the control group.

Although several effective therapies for treatment of these conditions already tap into the cognition-emotion partnership, it may be beneficial to continue exploring multiple therapeutic possibilities of using one system to modify the other. For example, in depression, awareness that one's emotional state interferes with the retrieval of joyful memories coupled with a clinical intervention designed to access these remembrances may help the patient improve.

\section{Principle 5: Bonding and Attachment Provide the Foundation for Change}

The term attachment is used to describe early caretaker-infant relationships as well as the psychological proximity that binds interpersonal relationships (Bowlby, 1969). During infancy, the intricate interpersonal connection between caregiver and infant has the capacity to start and modify corticolimbic and orbitofrontal circuitry in the brain (Schore, 2003). The corticolimbic and orbitofrontal regions of the brain have been associated with the regulation of emotion and bodily arousal. Given that these parts of the brain are not completely developed at birth, their development is susceptible to environmental experiences. Although early relationships set the neuronal systems to work and set the stage for future interpersonal attachment, these systems remain plastic throughout life. As a result, during adulthood, the therapeutic relationship may be seen as having the capacity to help clients modify neural systems, integrate neural functions, and enhance emotional regulation (Siegel, 1999).

Implications for clinical practice. From a neuroscientific perspective, the therapeutic relationship "can facilitate effective movement toward well-being and adaptive self-regulation" (Siegel, 1999, p. 285) by enhancing corticolimbic and orbitofrontal development. This neuroscience finding confirms studies that point to the thera- peutic relationship as the most reliable predictor of change in psychotherapy (Lambert, 1992; McCabe \& Priebe, 2004). In addition to the therapeutic effect, caring relationships in adulthood have the capacity to elicit positive physiological responses ranging from modifying circadian rhythms to enhancing recovery from an illness (Hofer \& Sullivan, 2001).

Whereas theoretical perspectives in psychology stress the significance of early attachment to varying degrees (Mitchell \& Black, 1996), few underscore the critical importance of the therapeutic bond. In some instances, elegant theories and techniques pale beside the vivid influence of genuine demonstrations of caring. The story of Maria provides one small example.

Maria was a woman in her 30s attending an intensive outpatient group three times per week for several months. Beset with thoughts of suicide, hopelessness, and low self-worth, she rarely spoke. When she did, she often ranted with false bravado about her life, alienating herself from other members of the group. Her attendance was sporadic. One morning during breakfast (the group regularly convened for breakfast prior to the formal group), having noticed that Maria had finished her coffee, the practitioner replenished Maria's cup and provided her with a few packets of sugar. Thereafter Maria's attendance improved, she began participating in earnest, and her depression lifted. After several weeks, Maria shared with the group that she considered the refreshment of her coffee a catalyst for change. This incidental act of kindness indicated to her, much more than the calculated interventions of the practitioner, that perhaps she was someone worth noticing and caring about.

\section{Principle 6: Imagery Activates and Stimulates the Same Brain Systems as Does Real Perception}

Imagery refers to the capacity to imagine an object that is not being perceived at that particular moment (Kosslyn, Ganis, \& Thompson, 2001). References to the "mind's eye" denote visual imagery so that one can conjure an image of a blue monkey in the absence of directly perceiving it. Perception, in contrast, is the process of acquiring, interpreting, and organizing actual sensory information such as vision, smell, taste, and touch.

In all likelihood, the various forms of imagery 
utilize distinct neurological pathways (see Kosslyn et al., 2001, for a review). Some studies point to a left temporo-occipital localization (Farah, 2000). More important, imagery processes use the same neural substrates as perception (Kreiman, Koch, \& Fried, 2000). Patterns of neural activation found in regions specific for the actual perception of faces are also activated during the process of imagining them (O'Craven \& Kanwisher, 2000). Similarly, brain regions known to be active during the perception of places are active during imagined versions of them (O'Craven \& Kanwisher, 2000).

The power of imagined events has been the focus of several pain management studies examining the effectiveness of placebo analgesia for the relief of chronic pain caused by illnesses such as cancer and spinal cord injury (Melzack \& Wall, 2003). Placebo analgesia refers to the practice of administering a placebo in the place of an analgesic (pain killer) (Benedetti \& Amanzio, 1997). Alternatively, a placebo response can be elicited by indicating that a substance is pain inducing. Under these circumstances, the recipient will complain of increased pain. The disciplines of health psychology and pain management currently utilize imagery techniques to relieve pain. In an experiment conducted by Ball, Shapiro, Monheim, and Weydert (2003), children with abdominal pain who used relaxation and imagery techniques experienced a $63 \%$ decrease in pain. The authors concluded that guided imagery techniques were an effective treatment for children with abdominal pain.

Implications for clinical practice. Whereas imagery techniques are already commonly used in psychological settings, these findings clarify why imagery is effective in treating conditions such as pain, fear, phobia, and anxiety. However, an understanding that imagined events differ little from actual perception also suggests that imagery techniques may yet be applied too narrowly. For example, a more creative use of imagery may be to cultivate empathy and compassion among practitioners for the experiences of their patients (i.e., to purposefully imagine being in the physical and emotional situation of the client). These can be practiced in the context of supervision and training, therefore enhancing one of the most critical aspects of psychotherapy, the therapeutic relationship.

In addition, detailed imagery techniques using sights, scents, and tactile sensation may be paired with other therapeutic techniques to enhance their effect; as in de Shazer's (1988) miracle question in which a patient is invited to describe his life after discovering that a miracle had occurred while he slept and his problems had vanished. The technique of envisioning a different life, be it to elicit empathy or hope, may as successfully invoke change as actual experience by virtue of stimulating the same neural substrates.

\section{Principle 7: The Brain Can Process Nonverbal and Unconscious Information}

Unconscious processes exert great influence on human thought, feeling, and action (Merikle \& Daneman, 2000). During the 1980s, rumors developed that advertising companies were using subliminal messages to sell more products (Guilloud, 2002). Whereas these marketing ventures were not as successful as expected, their campaigns were based on findings that the human brain has the capacity to perceive a stimulus outside of conscious awareness.

Studies concerning unconscious perception have relied heavily on the phenomena of priming. Priming refers to an action or response elicited by previously nonconsciously observed stimuli. The reaction will be related to the specific stimuli or with an event associated with it (Dudai, 2002). Priming is an automatic process that takes place unintentionally. For example, after watching a news report about a particular illness, a person is likely to interpret some body sensations as signs of that illness. Vallacher, Nowak, Froehlich, and Rockloff (2002) demonstrated the effects of priming on self-esteem and self-evaluations. In their experiment, participants were asked to relate either a positive or negative story about themselves and then provide a self-evaluation. Those who were asked to recall past self-acts (positive or negative) were more likely to report corresponding thoughts when asked to reflect on themselves. That is, participants who were asked to tell a positive story were more likely to describe a positive self-evaluation. The opposite was also true; people who were asked to present negative stories about themselves later reported a more negative self-evaluation. In the previous example, the priming experience was explicit (i.e., talk about a positive story). However, the stimuli or experiences that prime humans' subsequent behavior do not need to be consciously perceived.

What humans experience prior to an action can 
influence their subsequent choices. In addition, information processed unconsciously can still influence therapeutic and other encounters. Nonverbal behavior may be one of the great igniters of unconscious perception. Shea (1998) described many nonverbal activities and categorized them into the concepts of proxemics (referring to the proximity to another person), kinesics (referring to the bodily movements), and paralanguage (referring to the way the messages are delivered). These activities can inform human perception of a person and situation. For example, through observation of hand movements, proximity, and facial expressions, one can conclude that a person is anxious. These cues are not always consciously perceived nor are all forms of nonverbal behavior interpretable. However, it is possible to react to unconscious perception without conscious understanding of the reaction.

Implications for clinical practice. Given that a previously perceived stimulus disposes one to future responses, as in priming, a fertile area of research may be exploring the impact of a diagnostic clinical interview using a deficits-based approach. During diagnostic interviews, patients are asked to report symptoms and signs of impairment. Although informative, eliciting accounts of disability and distress from patients may exacerbate negative perceptions of self. Similarly, the finding that unconscious perception has the capacity to bring forth behavior may have implications for the physical environment. For example, researchers have recommended modifying the decor of mental health centers to render the atmosphere more inviting to underserved populations. Furthermore, outpatient clinics are often overflowing with brochures depicting numerous problems and symptomatology. According to this principle, an environment filled with positive information as opposed to one full of such negative content may render more positive results during the therapeutic session. Finally, unconscious perception suggests the importance of a genuine approach to therapy. Although practitioners customarily attend to the various forms of nonverbal communication of others, awareness of one's own idiosyncrasies may be more elusive, though apparent even to the untrained eye. Therefore, it becomes particularly important even through unspoken gestures to communicate positive regard for the patient.

\section{Conclusion}

Perhaps because of perceptions that neuroscience is esoteric and holds limited relevance to the practice of psychology, neuroscience has generally been relegated to a specialized branch of the psychology profession-neuropsychology. Yet neuroscience has the potential to inform clinical practice in myriad ways. Although for some readers the principles outlined in the above discussion may seem basic, what we hope to contribute are not the principles themselves but the use of neuroscience to improve practitioners' understanding of the processes underlying the experiences and behaviors of their clients and the mechanisms through which they can best effect change. Far from exhaustive, the principles presented here are intended to serve as a jumping off point for the further integration of neuroscience with the practice of clinical psychology. Beyond enhancing day-to-day practice, a potential point of expansion can include supporting current psychotherapeutic theories and techniques by uncovering their corresponding neurological substrates. At the same time, neuroscience can be used to inform the development of strategies, in psychotherapy and clinical training, that are consistent with the principles of brain functioning.

Psychology faces the challenge of understanding and treating the human being as a whole person with biological, psychological, social, cultural, and spiritual dimensions. An integrated biological and psychological science and practice captures these dimensions more fully, leading to a more accurate and comprehensive understanding of human beings while avoiding the simplistic reductionisms of the past. What then can psychotherapy learn from neuroscience? First and foremost that neuroscience can enhance the practice of psychology. It is within the purview of psychologists to understand both bodies of knowledge and to lead the way toward a more integrated science. Further, another important question is that of what neuroscience can learn from psychotherapy. By posing these questions and purposefully seeking their answers, researchers and practitioners can move toward a psychotherapeutic neuroscience.

\section{References}

Alpert, J. L., Brown, L. S., \& Courtois, C. A. (2000). Symptomatic clients and memories of childhood abuse: 
What the trauma and child sexual abuse literature tells us. Psychology, Public Policy, and Law, 4, 941-995.

American Psychiatric Association. (1994). Diagnostic and statistical manual of mental disorders (4th ed.). Washington, DC: Author.

Anderson, M. C., \& Green, C. (2001, March 15). Suppressing unwanted memories by executive control. $\mathrm{Na}$ ture, 410, 366-369.

Appell, D. (2002). Will knowing the genetic roots of mental illness increase stigma? Psychology Today, 35(4), 20.

Ball, T., Shapiro, D. E., Monheim, C. J., \& Weydert, J. A. (2003). A pilot study of the use of guided imagery for the treatment of recurrent abdominal pain in children. Clinical Pediatrics, 42, 527-532.

Benedetti, F., \& Amanzio, M. (1997). The neurobiology of placebo analgesia: From endogenous opioids to cholecystokinin. Progress in Neurobiology, 52, 109-125.

Bennett, A. (1897). On knowledge. Retrieved August 14, 2005, from http://home.earthlink.net/ anewhaus/ Aphorknowledge.htm

Bowlby, J. (1969). Attachment and loss: Vol. 1. Attachment. New York: Basic Books.

Brahams, D. (2000). "Repressed memories" and the law. Lancet, 356, 358.

Braun, K. A., Ellis, R., \& Loftus, E. (2002). Make my memory: How advertising can change our memories of the past. Psychology \& Marketing, 19, 1-23.

CAINE, R. N., \& CAINE, G. (1994). Making connections: Teaching and the human brain. Parsippany, NJ: Dale Seymour.

Conway, M. A. (2003). Commentary: Cognitiveaffective mechanisms and processes in autobiographical memory. Memory, 11, 217.

Cozzolino, L. J. (2002). The neuroscience of psychotherapy. New York: Norton.

Damasio, A. (2001, October 25). Fundamental feelings. Nature, 413, 781.

Damasio, A. (2003). Looking for Spinoza: Joy, sorrow, and the feeling brain. New York: Harcourt.

DAVIDSON, R. J., JACKSON, D. C., \& KALIN, N. H. (2000). Emotion, plasticity, context, and regulation: Perspectives from affective neuroscience. Psychological Bulletin, 126, 890-909.

DE SHAZER, S. (1988). Clues: Investigating solutions in brief therapy. New York: Norton.

Dudai, Y. (2002). Memory, from A to Z. New York: Oxford University Press.

Eichenbaum, H. (2001). The long and winding road to memory consolidation. Nature Neuroscience, 4, 10571058.

Eriksson, P. S., Perfilieva, E., Buörk-Eriksson, T., Alborn, A., Nordborg, C., Peterson, D. A., \& GaGe, F. H. (1998). Neurogenesis in the adult human hippocampus. Nature Medicine, 4, 1313-1317.

FARAH, M. J. (2000). The neural bases of mental imagery. In M. S. Gazzaniga (Ed.), The new cognitive neurosciences (2nd ed., pp. 965-974) Cambridge, MA: MIT Press.

Foa, E. B., Hearst-Ikeda, D., \& Perry, K. J. (1995). Evaluation of a brief cognitive behavioral program for the prevention of chronic PTSD in recent assault victims. Journal of Consulting and Clinical Psychology, 63, 948-955.
Frank, J. D., \& Frank, J. B. (1993). Persuasion and healing: A comparative study of psychotherapy (3rd ed.). Baltimore: Johns Hopkins University Press.

FreUd, S. (1949). An outline of psycho-analysis. New York: Norton.

GARRY, M., \& POLASChEK, D. (1999). Reinventing yourself: Who you are is limited only by your imagination. Psychology Today, 32(6), 65-69.

Gartside, S. E., LeItch, M. M., McQuade, R., \& SwarBRICK, D. J. (2003). Flattening the glucocorticoid rhythm causes changes in hippocampal expression of messenger RNAs coding structural and functional proteins: Implications for aging and depression. Neuropsychopharmacology, 28, 821-829.

Gilbertson, M. W., Shenton, M. E., Ciszewski, A., Kasai, K., Lasko, N. B., OrR, S. P., \& Pitman, R. K. (2002). Smaller hippocampal volume predicts pathologic vulnerability to psychological trauma. Nature Neuroscience, 5, 1242-1247.

Gonsalves, B., \& Paller, K. A. (2000). Neural events that underlie remembering something that never happened. Nature Neuroscience, 3, 1316-1321.

Gross, C. G. (2000). Neurogenesis in the adult brain: Death of a dogma. Nature Reviews Neuroscience, 1, 67-73.

Guilloud, S. (2002). Subliminal (read this) learning. Psychology Today, 35(2), 28.

Haist, F., Gore, J. B., \& MaO, H. (2001). Consolidation of human memory over decades revealed by functional magnetic resonance imaging. Nature Neuroscience, 4, 1139-1145.

Hofer, M. A., \& Sullivan, R. M. (2001). Toward a neurobiology of attachment. In C. A. Nelson \& M. Luciana (Eds.), Handbook of developmental cognitive neuroscience (pp. 599-616). Cambridge, MA: MIT Press.

Hyman, I. E., \& Pentland, J. (1996). The role of mental imagery in the creation of childhood memories. Journal of Memory and Language, 35, 101-117.

IngVar, M., \& Petterson, K. M. (2000). Functional maps and brain networks. In A. W. Toga \& J. C. Mazziotta (Eds.), Brain mapping the systems (pp. 111139). San Diego, CA: Academic Press.

KANDEL, E. R. (1998). A new intellectual framework for psychiatry. American Journal of Psychiatry, 155, 457469.

Kandel, E. R., Schwartz, J. H., \& Jessell, T. M. (2000). Principles of neural science. New York: McGraw-Hill.

KARASU, T. B. (1990). Toward a clinical model of psychotherapy for depression: II. An integrative and selective treatment approach. American Journal of Psychiatry, 147, 269-278.

Kosslyn, S. M., Ganis, G., \& Thompson, W. L. (2001). Neural foundations of imagery. Nature Reviews Neuroscience, 2, 635-642.

Kreiman, G., Koch, C., \& Fried, I. (2000, November 16). Imagery neurons in the human brain. Nature, 408 , 357-361.

LAMBERT, M. J. (1992). Implications of outcome research for psychotherapy integration. In J. C. Norcross \& M. R. Goldfield (Eds.), Handbook of psychotherapy integration (pp. 94-129). New York: Basic Books.

LEAKE, G. J., \& KING, A. S. (1977). Effect of counselor 
expectations on alcoholic recovery. Alcohol Health and Research World, 11(3), 16-22.

LE Doux, J. (1997). The emotional brain. New York: Simon \& Schuster.

LiNEHAN, M. M. (1993). Cognitive behavioral treatment of borderline personality disorder. New York: Guilford Press.

Loftus, E. (1997). Creating false memories. Scientific American, 277(3), 70-75.

LofTus, E. (2003). Our changeable memories: Legal and practical implications. Nature Reviews Neuroscience, 4, 231-234.

McCabe, R., \& Priebe, S. (2004). The therapeutic relationship in the treatment of severe mental illness: A review of methods and findings. International Journal of Social Psychiatry, 50, 115-128.

McEwen, B. S., \& SAPOlsky, R. M. (1995). Stress and cognitive function. Current Opinions in Neurobiology, 5, 205-216.

McGaugh, J. L. (2000, January 14). Memory-A century of consolidation. Science, 287, 248-251.

McGaugh, J. L., Cahill, L., \& RoozendaAl, B. (1996). Involvement of the amygdala in memory storage: Interaction with other brain systems. Proceedings of the National Academy of Sciences, USA, 93, 13508-13514.

Melzack, R., \& WALL, P. D. (2003). Handbook of pain management. New York: Elsevier Science.

Merikle, P. M., \& Daneman, M. (2000). Conscious vs. unconscious perception. In M. S. Gazzaniga (Eds.), The new cognitive neurosciences (2nd ed., pp. 1295-1303). Cambridge, MA: MIT Press.

Mitchell, S. A., \& Black, M. J. (1996). Freud and beyond: A history of modern psychoanalytic thought. New York: HarperCollins.

Morgan, A. (2000). What is narrative therapy? An easy to read introduction. Adelaide, South Australia: Dulwich Centre.

NADEL, L., \& LAND, C. (2000). Memory traces revisited. Nature Reviews Neuroscience, 1, 209-212.

O'Craven, K. M., \& Kanwisher, N. (2000). Mental imagery of faces and places activates corresponding stimulus-specific brain regions. Journal of Cognitive Neuroscience, 12, 1023-1034.

PAYKel, E. S. (1995). Psychotherapy, medication combinations, and compliance. Journal of Clinical Psychiatry, 56(Suppl. 1), 24-30.

RYABININ, A. E. (1998). Role of hippocampus in alcoholinduced memory impairment: Implications from behavioral and immediate early gene studies. Psychopharmacology, 139, 34-43.

SAPOLSKY, R. M. (1998). Why zebras don't get ulcers: An updated guide to stress, stress-related diseases, and coping. New York: Freeman.

Scheflin, A. W., \& Brown, D. (1996). Repressed memory or dissociative amnesia: What the science says. Journal of Psychiatry and Law, 24, 143-188.

SCHORE, A. (2003). Affect dysregulation and disorders of the self. New York: Norton.

SHACTER, D. L. (1996). Searching for memory. New York: Basic Books.

SHEA, S. C. (1998). Psychiatric interviewing: The art of understanding. Philadelphia: Saunders.

SiEgel, D. J. (1999). The developing mind. New York: Guilford Press.

Squire, L. R., \& Kandel, E. R. (1999). Memory: From mind to molecules. New York: Scientific \& American Library.

Vallacher, R. R., Nowak, A., Froehlich, M., \& RocKLOFF, M. (2002). The dynamics of self-evaluation. Personality \& Social Psychology Review, 6, 370-380.

VAN DER KolK, B., \& FISLER, R. (1995). Dissociation and the fragmentary nature of traumatic memories: Overview and exploratory study. Journal of Traumatic Stress, 8, 505-525.

Van Praag, H., Schinder, A. F., Christie, B. R., Toni, N., PAlmer, T. D., \& Gage, F. H. (2002, February 28). Functional neurogenesis in the adult hippocampus. $\mathrm{Na}$ ture, 415, 1030-1034.

Wilson, J. P., Raphael, B., Meldrum, L., Bedosky, C., \& Sigman, M. (2000). Preventing PTSD in trauma survivors. Bulletin of the Menninger Clinic, 64, 181-197. 